Part of Journal of Research of the National Bureau of Standards, Volume 25,

\title{
EFFECT OF COMPOSITION AND OTHER FACTORS ON THE SPECIFIC REFRACTION AND DISPERSION OF GLASSES
}

\author{
By John C. Young and Alfred N. Finn
}

\begin{abstract}
Seven of the better known specific-refraction ratios were examined for their comparative applicability to glass. It is shown by a comprehensive statistical treatment of available data (including many new data) that, of these ratios, only the Gladstone-Dale possesses to a satisfactory degree each of the following desirable features: (1) It varies linearly with chemical composition and with the square of the wave number of the incident light; (2) for a given composition and wavelength of light, it is substantially the same for both the vitreous and crystalline states; and (3) for the vitreous state, it is independent of thermal history. Gladstone-Dale factors for 47 oxides as constituents of glass (and corresponding factors derived from nonglassy substances) are given. These factors are shown to be related to the periodicity of the elements. Specific dispersion factors, useful for computing the dispersion index, or $\nu$-value, of a glass are given for 32 oxides.
\end{abstract}

\section{CONTENTS}

Page

I. Introduction

II. Source material

III. Correlation of the data

1. Chemical composition

2. Heat treatment_._.

3. Vitreous and crystalline states

(a) Oxides

(b) Elements_...

4. Wavelength of light

IV. Relation of the Gladstone-Dale ratio to the periodic arrangement of the

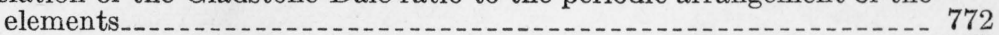

V. Relation of dispersion to specific refraction and to composition

VI. Summary _._. 781

VII. References_... 781

\section{INTRODUCTION}

Many attempts have been made to link the refractive index and density of a substance in such a way that the proposed relationship, frequently called specific-refraction or specific-refractive power, would possess, among other features, the following: (1) It would be constant for a given substance and wavelength of light when certain other conditions are varied; (2) it would bear an additive relationship to the chemical composition of a substance and vary linearly with some simple function of the wavelength of light. A great deal has been written on the subject in its application to gases and liquids since Gladstone and Dale developed their well-known theorem [1]. ${ }^{1}$ Larsen and Berman [2] determined the Gladstone-Dale ratio for hundreds

1 Numbers in brackets indicate the literature references at the end of this paper. 
of minerals and calculated factors for the constituent oxides. But in the field of glass technology, despite the apparent wealth of data, similar work has been confined to a very few of the commoner oxides. Morey and Merwin [3] calculated specific-refraction factors for sodalime-silica glasses, using the Gladstone-Dale and other proposed formulas. More recently Wulff and Majumdar [4] applied the Lorentz-Lorenz formula to a few soda-boric-oxide glasses, while Biltz and Weibke [5], using principally the data of others, calculated Gladstone-Dale factors for $\mathrm{Na}_{2} \mathrm{O}, \mathrm{K}_{2} \mathrm{O}, \mathrm{CaO}, \mathrm{B}_{2} \mathrm{O}_{3}$, and $\mathrm{SiO}_{2}$. Randall and Gee [6] utilized the Lorentz-Lorenz ratio in connection with atomic size for calculating the refractive index of glasses containing $\mathrm{PbO}$ in addition to the oxides just enumerated. Still more recently, Kordes [7] studied the variation in the Lorentz-Lorenz ratio of glasses with composition; he obtained some data on glasses in the binary systems $\mathrm{PbO}-\mathrm{B}_{2} \mathrm{O}_{3}, \mathrm{ZnO}-\mathrm{B}_{2} \mathrm{O}_{3}, \mathrm{CdO}-\mathrm{B}_{2} \mathrm{O}_{3}, \mathrm{PbO}-\mathrm{SiO}_{2}$, and $\mathrm{PbO}-\mathrm{P}_{2} \mathrm{O}_{5}$, and expressed his results by some rather complicated empirical equations.

The results of none of these investigations, however, have a general application, owing to the limited fields of composition studied. It was the purpose of the present research, therefore, to determine, by a comprehensive statistical study of all available data, how a number of the proposed specific-refraction relationships apply, under a variety of conditions, to glass and glass-forming materials.

The specific refraction $(R)$ type ratios considered are:

$$
\begin{array}{ll}
\frac{n-1}{D} & \text { Gladstone-Dale [1] } \\
\frac{n^{2}-1}{n^{2}+2} \cdot \frac{1}{D} & \text { Lorentz-Lorenz [8,9] } \\
\frac{\log n}{D} & \text { Lichtenecker [10] } \\
\frac{n^{2}-1}{n+0.4} \cdot \frac{1}{D} & \text { Eykman [11] } \\
\frac{n^{2}-1}{D} & \text { Newton [12] } \\
\frac{\sqrt{n}-1}{D} & \text { Johst [13] } \\
\frac{n-1}{n D} & \text { Edwards [14] }
\end{array}
$$

In these formulas, $n$ and $D$ are refractive index and density, respectively. Unless otherwise stated, $n$ is for sodium light.

The variables considered, which might influence the various specific refraction ratios of a glass or oxide, are changes in (1) chemical composition, (2) heat treatment, (3) vitreous and crystalline states, and (4) wavelength of light.

No data are presented here on the effect of temperature on the different type ratios. It is a well-established fact [40] that, whereas 
the density of a glass decreases continuously with rising temperature, there is usually a corresponding decrease in the refractive index only in the rapid-expansion range. Therefore, for most glasses, none of the type ratios could remain constant or vary linearly with increasing temperatures, except possibly for certain limited temperature ranges.

\section{SOURCE MATERIAL}

The data on glass herein considered were collected from many sources, references to which are given at the end of this paper. References not specifically mentioned in the text are indicated in tables 2 and 8, under the heading "Source of glass data."

The symbol " $s$ " in tables 2 and 8 refers to unpublished data on certain of the more unusual oxides incorporated in glasses made especially for this study. For each of these glasses, one of the special oxides was added to a parent glass having the composition 71.5 percent of $\mathrm{SiO}_{2}, 18.3$ percent of $\mathrm{Na}_{2} \mathrm{O}$, and 10.2 percent of $\mathrm{CaO}$ (weight percentages), the amount added varying with the different glasses of a given series up to the maximum percentage indicated. All of these glasses were made from materials of known composition, but only the glasses containing $\mathrm{Rb}_{2} \mathrm{O}, \mathrm{Cs}_{2} \mathrm{O}$, $\mathrm{ThO}_{2}$, and $\mathrm{ZrO}_{2}$ were analyzed.

The symbol " $u$ " in the tables refers to unpublished data obtained at this Bureau on a wide variety of glasses containing only the more common oxides. Nearly all of these glasses were analyzed.

The symbol " $g$ " in the tables refers to some data on natural glasses, the compositions of which are given by Washington [37], and the corresponding densities and refractive indices by George [38].

The data on crystalline and liquid compounds are taken almost exclusively from the International Critical Tables [36].

\section{CORRELATION OF THE DATA}

\section{CHEMICAL COMPOSITION}

To determine the relative degree of linearity of the relationship between chemical composition and the various type ratios, two series of binary glasses were first studied, a series of 51 soda-silica, and a series of 35 potash-silica glasses, whose densities (but not the corresponding refractive indices) and compositions have been reported recently by this Bureau [15]. Figure 1 shows the results obtained by plotting the specific refractions of the glasses in each series, as computed from the seven type formulas previously mentioned, against the composition (silica content) of the glasses. The individual specific refraction values, $R$, for these two series of glasses, together with those of 60 additional glasses containing all three of these constituents $\left(\mathrm{Na}_{2} \mathrm{O}, \mathrm{K}_{2} \mathrm{O}\right.$ and $\left.\mathrm{SiO}_{2}\right)$ [15], were used to determine, by a least squares solution, the unknown constants of the equation.

$$
R=1 / 100\left(r_{A} p_{A}+r_{B} p_{B}+r_{E} p_{E}\right),
$$

for each of the type ratios (except the Newton and the Edwards). The $p$ 's are the weight percentages of silica, $A$; soda, $B$; and potash, $E$, respectively, and the $r$ 's are constants which may be considered as the 
specific refraction factors of the respective oxides. In each solution the respective factor for silica, $r_{A}$, was considered as "known", and was obtained from the most probable values of the refractive index

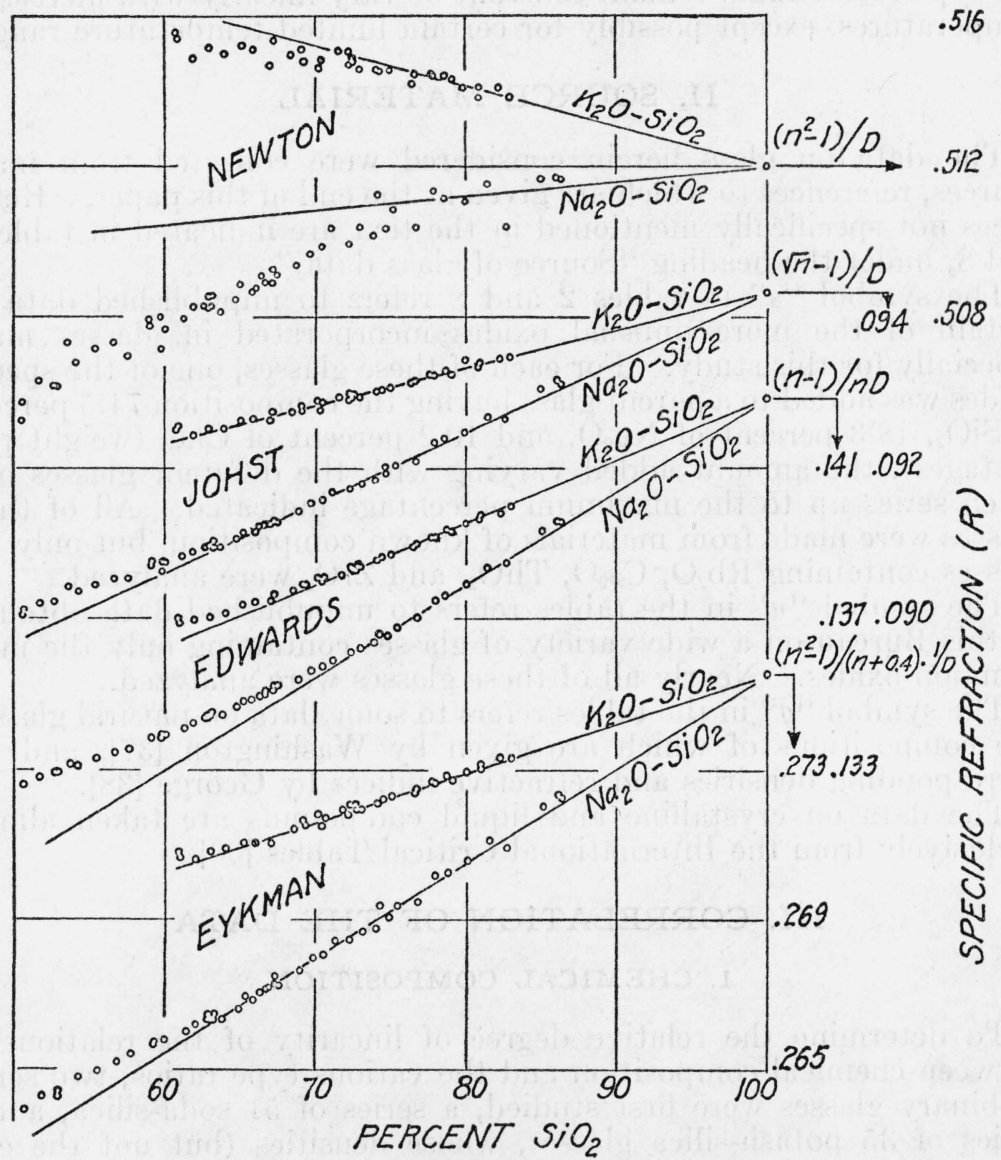

FIgURE 1.-Relation between specific refraction $(R)$, calculated from the various formulas and compositions, for a series of soda-silica and a series of potash-silica glasses made at the National Bureau of Standards [15].

and of the density of vitreous silica [18], that is, 1.4585 and 2.2026, respectively. The results of these calculations are shown in table 1.

TABLE 1.-Values of constants for eq 1, and average deviation between observed and calculated specific refractions $(R)$ for 146 soda-potash-silica glasses

\begin{tabular}{|c|c|c|c|c|c|}
\hline Type ratio $(R)$ & $r_{\Delta}$ & $r_{B}$ & $r_{\mathbf{w}}$ & $\begin{array}{c}\text { Average } \\
\text { percentage } \\
\text { deviation } \\
\text { from } \\
\text { observed } \\
R^{\prime} s\end{array}$ & $\begin{array}{l}\text { Average } \\
\text { deviation } \\
\text { in terms } \\
\text { of } n_{D}\end{array}$ \\
\hline 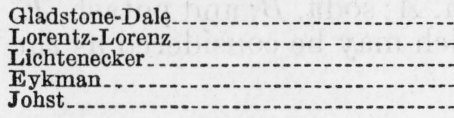 & $\begin{array}{l}0.20815 \\
.12400 \\
.07444 \\
.27537 \\
.09430\end{array}$ & $\begin{array}{r}0.19365 \\
.11025 \\
.06584 \\
.25123 \\
.08533\end{array}$ & $\begin{array}{r}0.20185 \\
.11585 \\
.06894 \\
.26267 \\
.08931\end{array}$ & $\begin{array}{l}0.045 \\
.092 \\
.100 \\
.065 \\
.070\end{array}$ & $\begin{array}{l}0.00025 \\
.0006 \\
.0007 \\
.0004 \\
.0007\end{array}$ \\
\hline
\end{tabular}


It is evident from table 1 that the average percentage deviation for the Gladstone-Dale ratio is about two-thirds that for the Eykman, and about half those for the Lorentz-Lorenz, Lichtenecker, and Johst

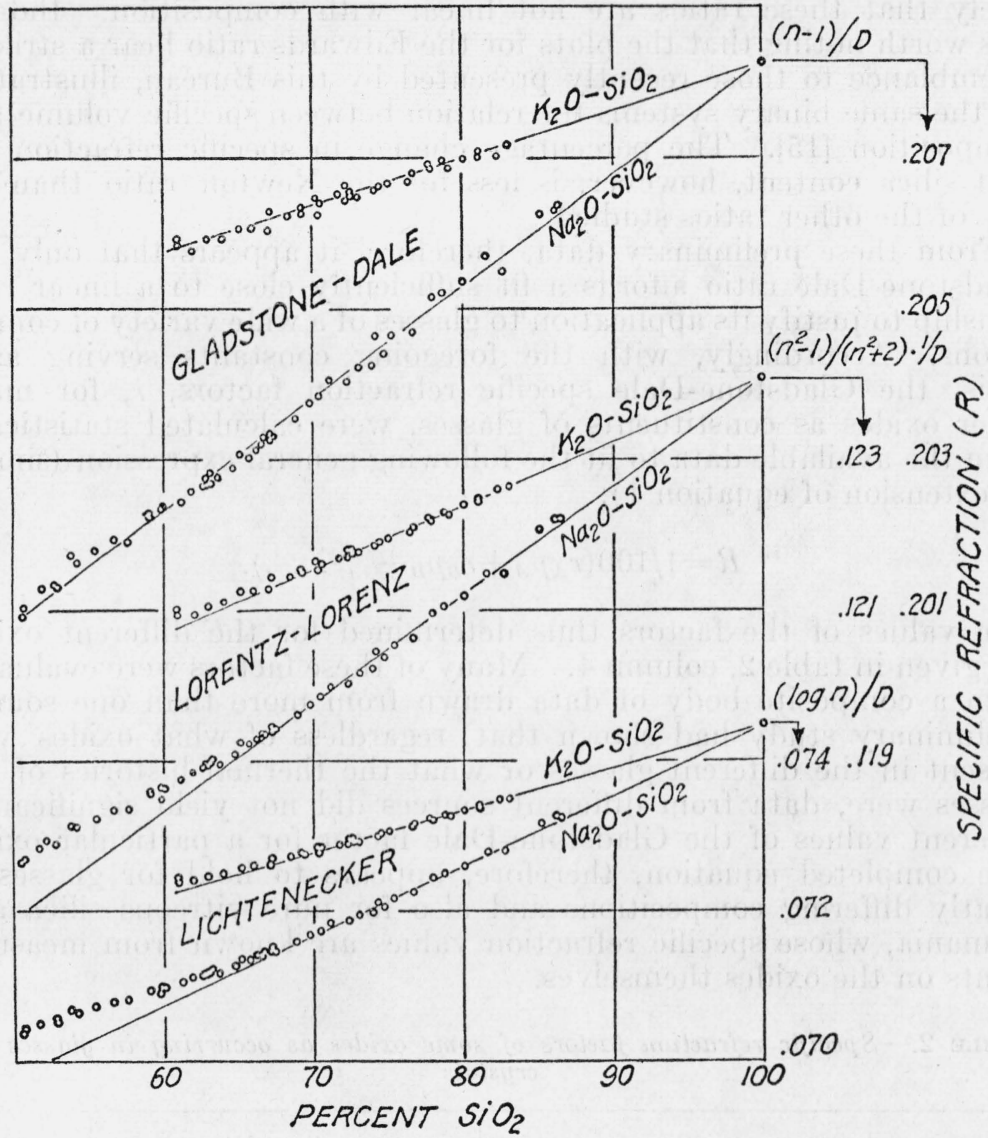

Figure 1.-(Continued)

ratios. Moreover, the deviations for the latter four type ratios appear to be highly systematic (as shown in part by fig. 1 ) ${ }^{2}$ while the "average deviation in terms of $n_{D}$ " is sufficiently small to be comparable to the experimental error in refractive index (about 0.0002 ) for the Gladstone-Dale ratio only. Although the average percentage deviations shown in table 1 are somewhat less than those found by Morey and Merwin for a series of soda-lime-silica glasses (they did not consider the Johst ratio), the values of the constants for the soda-silica glasses, and the relative "goodness of fit" of the straight lines for the various type formulas, are in good agreement with the findings of those investigators.

3 The straight lines were drawn in figure 1 merely to show visually the departure of the plotted points from linearity and have no connection with the constants given above. 
No similar computations were made for the Newton and the Edwards type ratios for, while there may be some justification for fitting straight lines to the points of the potash-silica data, an inspection of the respective graphs for the soda-silica glasses shows rather decisively that these ratios are not linear with composition. Indeed, it is worth noting that the plots for the Edwards ratio bear a striking resemblance to those recently presented by this Bureau, illustrating for the same binary systems the relation between specific volume and composition [15]. The percentage change in specific refraction per unit silica content, however, is less for the Newton ratio than for any of the other ratios studied.

From these preliminary data, therefore, it appears that only the Gladstone-Dale ratio affords a fit sufficiently close to a linear relationship to justify its application to glasses of a wide variety of compositions. Accordingly, with the foregoing constants serving as a basis, the Gladstone-Dale specific refraction factors, $r$, for many other oxides as constituents of glasses, were calculated statistically from the available data to fit the following general expression (simply an extension of equation 1 ):

$$
R=1 / 100\left(r_{A} p_{A}+r_{B} p_{B}+\ldots\right) .
$$

The values of the factors thus determined for the different oxides are given in table 2, column 4. Many of these factors were evaluated from a composite body of data drawn from more than one source. Preliminary study had shown that, regardless of what oxides were present in the different glasses or what the thermal histories of the glasses were, data from different sources did not yield significantly different values of the Gladstone-Dale factor for a particular oxide. The completed equation, therefore, appears to hold for glasses of greatly differing compositions and also for pure vitreous silica and germania, whose specific refraction values are known from measurements on the oxides themselves.

TABLE 2.-Specific refraction factors of some oxides as occurring in glasses and crystals

\begin{tabular}{|c|c|c|c|c|c|c|c|}
\hline \multirow[b]{2}{*}{ Oxide } & \multicolumn{3}{|c|}{ Glass } & \multicolumn{3}{|c|}{ Crystal } & \multirow[b]{2}{*}{$\begin{array}{l}\text { Source of } \\
\text { glass data b }\end{array}$} \\
\hline & $\begin{array}{c}\text { Number } \\
\text { of glasses } \\
\text { containing } \\
\text { oxide }\end{array}$ & $\begin{array}{l}\text { Maximum } \\
\text { percent- } \\
\text { age }\end{array}$ & $\begin{array}{c}r \\
\text { (Gladstone- } \\
\text { Dale) }\end{array}$ & $\begin{array}{c}\text { Number of } \\
\text { compounds } \\
\text { containing } \\
\text { oxide }\end{array}$ & 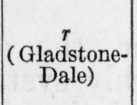 & $\begin{array}{c}r \\
\text { (Lorenz- } \\
\text { Lorentz) }\end{array}$ & \\
\hline 1 & 2 & 3 & 4 & 5 & 6 & 7 & 8 \\
\hline $\begin{array}{l}\mathrm{H}_{2} \mathrm{O} \\
\mathrm{Li}_{2} \mathrm{O} \\
\mathrm{Na}_{2} \mathrm{O} \\
\mathrm{K}_{2} \mathrm{O} \\
\mathrm{Rb}_{2} \mathrm{O} \\
\mathrm{Cs}_{2} \mathrm{O} \\
\mathrm{Tl}_{2} \mathrm{O} \\
\left(\mathrm{NH}_{4}\right)_{2} \mathrm{O}_{2}\end{array}$ & $\begin{array}{r}3 \\
11 \\
111 \\
95 \\
3 \\
2 \\
5 \\
\end{array}$ & $\begin{array}{r}9 \\
26 \\
50 \\
40 \\
55 \\
60 \\
55\end{array}$ & $\begin{array}{l}0.344 \\
.308 \\
.1937 \\
.2019 \\
.133 \\
.124 \\
.148 \\
-.-\end{array}$ & \begin{tabular}{r|r}
128 \\
8 \\
24 \\
21 \\
13 \\
13 \\
7 \\
74
\end{tabular} & $\begin{array}{r}0.345 \\
.293 \\
.197 \\
.204 \\
.134 \\
.130 \\
.120 \\
.542\end{array}$ & $\begin{array}{r}0.231 \\
.156 \\
.193 \\
.099 \\
.086 \\
\\
\end{array}$ & $\begin{array}{l}g \\
u \\
u[15] \\
u[15] \\
u \\
u \\
u[31] \\
\end{array}$ \\
\hline $\begin{array}{l}\mathrm{BeO} \\
\mathrm{MgO} \\
\mathrm{CaO} \\
\mathrm{ZnO} \\
\mathrm{SrO}\end{array}$ & $\begin{array}{r}44 \\
26 \\
46 \\
28 \\
4\end{array}$ & $\begin{array}{l}16 \\
40 \\
56 \\
65 \\
63\end{array}$ & $\begin{array}{l}.236 \\
.212 \\
.2270 \\
.150 \\
.154\end{array}$ & $\begin{array}{r}5 \\
34 \\
36 \\
12 \\
3\end{array}$ & $\begin{array}{l}.232 \\
.217 \\
.228 \\
.156 \\
.151\end{array}$ & $\begin{array}{l}.126 \\
.136 \\
.095 \\
\end{array}$ & $\begin{array}{c}{[24,25]} \\
u[33] \\
{[3,16,17]} \\
u[7,21,34] \\
u[32]\end{array}$ \\
\hline
\end{tabular}

See footnotes at end of table. 
TABLE 2.-Specific refraction factors of some oxides as occurring in glasses and crystals - Continued

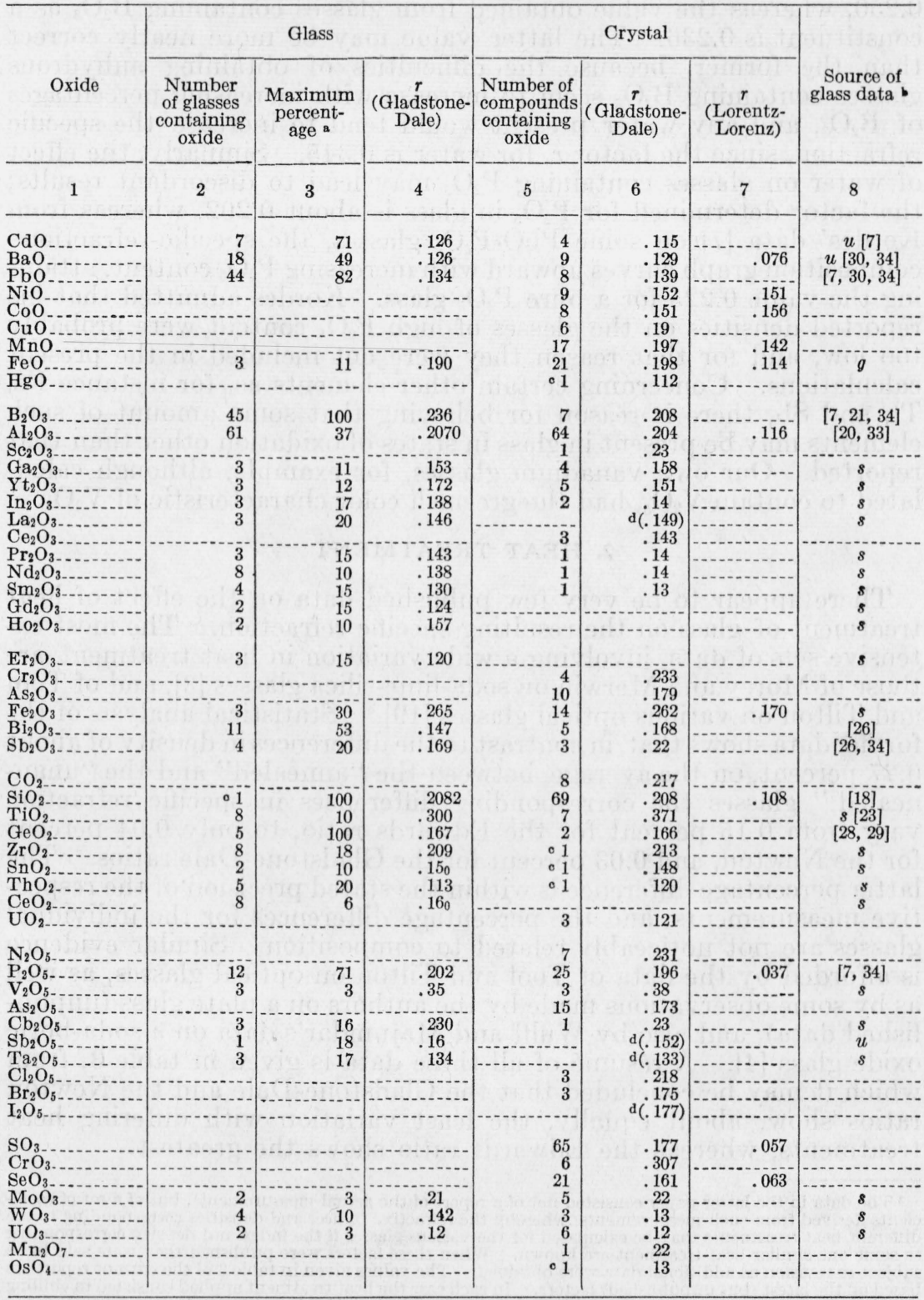

a Figures in this column indicate for each oxide the maximum percentage reported in the literature referred to in column 8; validity of the factor is not necessarily confined to such maximum.

b Numbers in brackets indicate references at the end of this paper; $s$ indicates unpublished data on special glasses made at this Bureau (see section II); $u$ indicates other unpublished data obtained at this Bureau; $g$ indicates data from natural glasses [37, 38]; all crystal data are from International Critical Tables.

c Pure oxide.

d From Larsen and Berman [2]. 
The most discordant data are those involving $\mathrm{B}_{2} \mathrm{O}_{3}$; the various measurements on the pure oxide give an average value for $r$ of about 0.250 , whereas the value obtained from glasses containing $\mathrm{B}_{2} \mathrm{O}_{3}$ as a constituent is 0.236 . The latter value may be more nearly correct than the former, because the difficulties of obtaining anhydrous glasses containing $\mathrm{B}_{2} \mathrm{O}_{3}$ seem to increase with increasing percentages of $\mathrm{B}_{2} \mathrm{O}_{3}$, and any water present would tend to increase the specific refraction, since the factor $r$, for water is 0.345 . Similarly, the effect of water on glasses containing $\mathrm{P}_{2} \mathrm{O}_{5}$ may lead to discordant results; the factor determined for $\mathrm{P}_{2} \mathrm{O}_{5}$ in glass is about 0.202 , whereas from Kordes' data [7] on some $\mathrm{PbO}-\mathrm{P}_{2} \mathrm{O}_{5}$ glasses, the specific-refractioncomposition graph curves upward with increasing $\mathrm{P}_{2} \mathrm{O}_{5}$ content, attaining the value 0.225 for a pure $\mathrm{P}_{2} \mathrm{O}_{5}$ glass. Kordes admitted that his reported densities on the glasses of high $\mathrm{P}_{2} \mathrm{O}_{5}$ content were probably too low, and for that reason they were not included in the present calculations. Concerning certain other elements as, for instance $\mathrm{Fe}$, $\mathrm{Tl}$, and $\mathrm{Sb}$, there is reason for believing that some amount of such elements may be present in glass in states of oxidation other than that reported. Our own vanadium glasses, for example, although calculated to contain $\mathrm{V}_{2} \mathrm{O}_{5}$, had the greenish color characteristic of $\mathrm{V}_{2} \mathrm{O}_{3}$.

\section{HEAT TREATMENT}

There appear to be very few published data on the effect of heat treatment of glass on the resulting specific refraction. The most extensive sets of data, involving a wide variation in heat treatment, are those of Morey and Merwin on soda-lime-silica glasses [3], and of Tool and Tilton on various optical glasses [19]. ${ }^{3}$ Statistical analysis of the former data shows that, in contrast to the differencesin density of about 0.27 percent, on the average, between the "annealed" and the "unannealed," glasses the corresponding differences in specific refraction vary from 0.15 percent for the Edwards ratio, to only 0.04 percent for the Newton, and 0.03 percent for the Gladstone-Dale ratios. The latter percentage difference is within the stated precision of the respective measurements, and the percentage differences for the individual glasses are not noticeably related to composition. Similar evidence is afforded by the data of Tool and Tilton on optical glasses, as well as by some observations made by the authors on a plate glass (unpublished data), and also by Wulff and Majumdar's data on a soda-boric oxide glass [4]. A résumé of all these data is given in table 3, from which it may be concluded that the Gladstone-Dale and the Newton ratios show, about equally, the least variation with differing heat treatments, whereas the Edwards ratio shows the greatest.

3 The data in the latter paper consisted not of a report of the actual measurements, but of a set of coefficients derived from such measurements, whereby the refractive indices and densities corresponding to the different heat treatments may be calculated for the various glasses if the index and density corresponding to some one similar heat treatment are known. When these factors were published they were said to be subject to revision as additional data were obtained. The values given in table 3 of the current report are based on the latest (but unpublished) factors. In each case the heat treatment applied consisted in chilling the glass from a given temperature after approximate equilibrium had been attained. 
TABLE 3.-Effect of heat treatment on specific refractions $(R)$ of various glasses

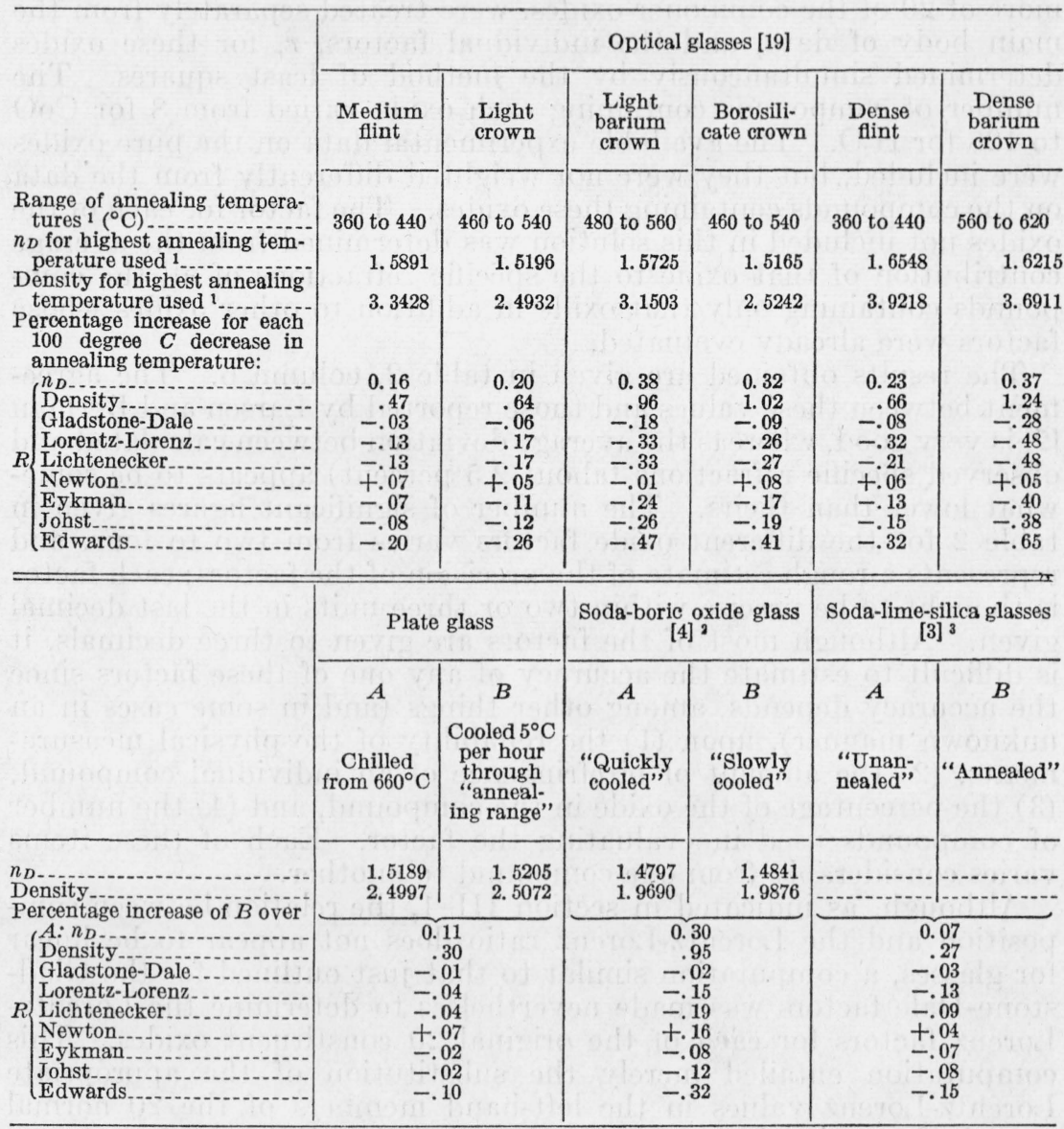

1 Measurements of $n_{D}$ and density made after sample was cooled quickly from annealing temperature. See text footnote 3 .

${ }_{2}$ The composition of this glass is given as $93.2 \%$ of $\mathrm{B}_{2} \mathrm{O}_{3}$ and $6.8 \%$ of $\mathrm{Na}_{2} \mathrm{O}$.

3 Figures under this heading represent averages based on the entire series of glasses.

\section{VITREOUS AND CRYSTALLINE STATES}

\section{(a) OXIDES}

Assuming a linear relationship with composition, as in section III-1, the Gladstone-Dale ratios for 60 oxides were calculated from the data on about 400 crystalline oxides and compounds reported in the International Critical Tables. The compounds considered were only those consisting of two or more of the oxides listed in table 2, and for convenience will be referred to as "oxide-compounds." The refractive index used for each compound was the mean index for the crystal (that is $(2 \omega+\epsilon) / 3$ or $(\alpha+\beta+\gamma) / 3)$, but in general the data were not used for crystals whose birefringence exceeded 0.04 in refractive index. 
The data on more than 200 of these compounds, containing one or more of 20 of the commoner oxides, were treated separately from the main body of data, and the individual factors, $r$, for these oxides determined simultaneously by the method of least squares. The number of compounds containing each oxide varied from 8 for $\mathrm{CoO}$ to 128 for $\mathrm{H}_{2} \mathrm{O}$. The available experimental data on the pure oxides were included, but they were not weighted differently from the data on the compounds containing these oxides. The factor for each of the oxides not included in this solution was determined from the average contribution of that oxide to the specific refractions of all the compounds containing only that oxide in addition to other oxides whose factors were already evaluated.

The results obtained are given in table 2, column 6 . The agreement between these values and those reported by Larsen and Berman [2] is very good, whereas the average deviation between calculated and observed specific refractions (about 2.5 percent) appears to be somewhat lower than theirs. The number of significant figures given in table 2 for the different oxide factors varies from two to four, and represents a rough estimate of the precision of the factors; each factor is thought to be precise within two or three units in the last decimal given. Although most of the factors are given to three decimals, it is difficult to estimate the accuracy of any one of these factors since the accuracy depends, among other things (and in some cases in an unknown manner), upon (1) the reliability of the physical measurements, (2) the amount of birefringence of an individual compound, (3) the percentage of the oxide in the compound, and (4) the number of compounds used in evaluating the factor. Each of these items varies considerably from one compound to another.

Although, as indicated in section III-1, the relation between composition and the Lorentz-Lorenz ratio does not appear to be linear for glasses, a computation similar to that just outlined for the Gladstone-Dale factors was made nevertheless to determine the LorentzLorenz factors for each of the original 20 constituent oxides. This computation entailed merely the substitution of the appropriate Lorentz-Lorenz values in the left-hand members of the 20 normal equations previously set up for the Gladstone-Dale ratio, and performing the necessary numerical operations. The factors thus found for these oxides are given in table 2, column 7 . It was found, however, that the average deviation between the observed and the calculated values for the Lorentz-Lorenz ratio was over 7 percent, which is almost three times that for the Gladstone-Dale ratio. Moreover, in most cases the Lorentz-Lorenz oxide-factors obtained by solving the normal equations are considerably different from the corresponding values for the pure oxides - a further evidence that the LorentzLorenz specific-refraction-composition relationship is not linear. The foregoing calculations for the Lorentz-Lorenz factors were made principally because this type ratio is widely favored for a variety of purposes, and for certain limited applications has some theoretical foundation, but no similar computations for the other type ratios were attempted. 
It should be noted from table 2 that in most cases the GladstoneDale factor, $r$, for an oxide in a crystalline compound, is not markedly different from that of the same oxide as a constituent of glass. A partial explanation for most of the large discrepancies found has already been indicated in section III-1. Concerning observations on the pure oxides, refractive index and density data for both the crystalline and vitreous state appear to be limited to those on $\mathrm{SiO}_{2}$, and these data are accordingly reported in table 4, together with the corresponding values for all the type ratios studied. Table 4 indicates that the Gladstone-Dale ratio is substantially the same for both vitreous $\mathrm{SiO}_{2}$ and the various modifications of crystalline $\mathrm{SiO}_{2}$. Moreover, as between quartz and vitreous silica, the order of placement (by percentage difference) of the various type ratios is about the same as that found for heat treatment of glasses-least for the GladstoneDale ratio, greatest for the Edwards. It might be mentioned in passing that this correspondence is not surprising, since the different states might be regarded in a sense as the outcome of different "heat treatments."

TABLE 4.-Specific refractions of vitreous and crystalline $\mathrm{SiO}_{2}$

\begin{tabular}{|c|c|c|c|c|c|c|c|c|c|}
\hline & \multirow[b]{2}{*}{$n_{D}$} & \multirow[b]{2}{*}{$\begin{array}{l}\text { Den- } \\
\text { sity }\end{array}$} & \multicolumn{7}{|c|}{ Specific refraction $(R)$} \\
\hline & & & $\begin{array}{l}\text { Glad- } \\
\text { stone- } \\
\text { Dale }\end{array}$ & $\begin{array}{l}\text { Lorentz- } \\
\text { Lorenz }\end{array}$ & $\begin{array}{l}\text { Lichte- } \\
\text { necker }\end{array}$ & Newton & Eykman & Johst & $\begin{array}{c}\text { Ed- } \\
\text { wards }\end{array}$ \\
\hline $\begin{array}{l}\text { (A) Vitreous silica } \\
\text { (B) Tridymite } \\
\text { (D) Cristobalite } \\
\text { Percentage increase of } \\
\text { Percenta } \\
(D) \text { over }(A)\end{array}$ & $\begin{array}{l}1.4585 \\
1.470 \\
1.486 \\
1.547 \\
6.0\end{array}$ & $\begin{array}{l}2.203 \\
2.26 \\
2.32 \\
2.651 \\
20.5\end{array}$ & $\begin{array}{r}0.2081 \\
.2080 \\
.2094 \\
.2064 \\
-0.8\end{array}$ & $\begin{array}{r}0.1240 \\
.1234 \\
.1238 \\
.1197 \\
-3.5\end{array}$ & $\begin{array}{r}0.0744 \\
.0740 \\
.0741 \\
.0715 \\
-3.9\end{array}$ & $\begin{array}{r}0.5117 \\
.5137 \\
.5208 \\
.5257 \\
+2.7\end{array}$ & $\begin{array}{r}0.2753 \\
.2747 \\
.2761 \\
.2700 \\
-2.0\end{array}$ & $\begin{array}{r}0.0943 \\
.0940 \\
.0944 \\
.0920 \\
-2.5\end{array}$ & $\begin{array}{r}0.1427 \\
.1415 \\
.1410 \\
.1334 \\
-6.5\end{array}$ \\
\hline
\end{tabular}

(b) ELEMENTS

Thus far the oxide has been taken as the basic unit for a glass or compound. Assuming that the specific refraction (Gladstone-Dale) of a compound is an additive function of the specific refractions of its constituent elements, the atomic refraction, $m r^{\prime}$, for each of the various elements was evaluated statistically to fit the formula,

$$
M R=n_{a} m_{a} r_{a}{ }^{\prime}+n_{b} m_{b} r_{b}{ }^{\prime}+\ldots .
$$

For each compound, $M$ and $R$ are the molecular weight and specific refraction, respectively, and $m, n$, and $r^{\prime}$ are the atomic weight, number of atoms, and specific refraction factor ("element-factor") of each of the elements $a, b$, etc., occurring in the compound. The data used were derived from about 300 miscellaneous crystalline and liquid compounds, including halides and metal-organic compounds, listed in the International Critical Tables, and for convenience will be referred to as "miscellaneous compounds"; but none of those described above as "oxide compounds" was included. The values of atomic refraction, $m r^{\prime}$, thus found are given in table 5, column 4 . 
TABLE 5.-Atomic refraction factors $\left(m r^{\prime}\right)$

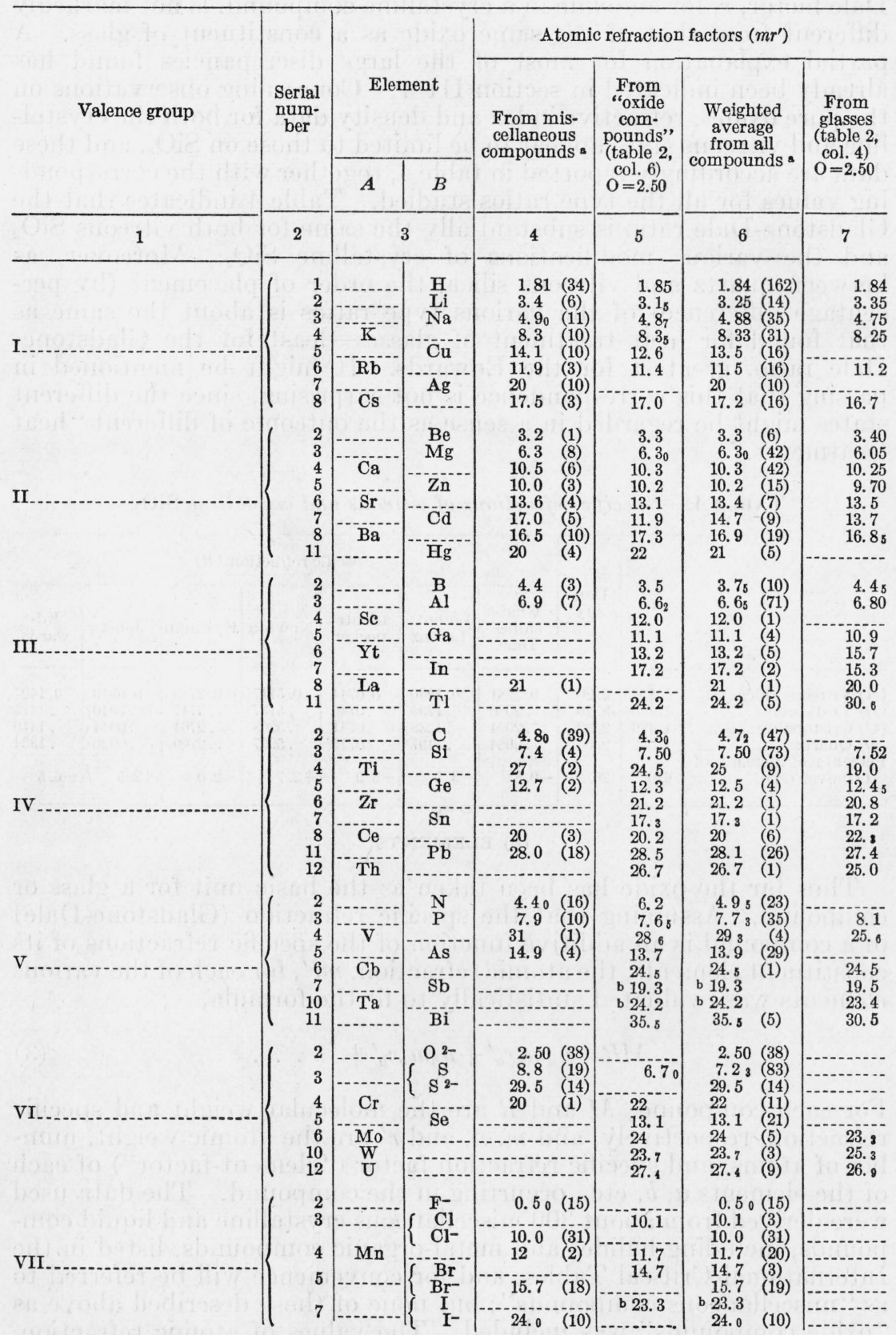

s Numbers in parentheses after factor indicate number of compounds used in evaluating that factor.

b From oxide values given by Larsen and Berman [2]. 
TABLE 5.-Atomic refraction factors $\left(m r^{\prime}\right)$ - Continued

\begin{tabular}{|c|c|c|c|c|c|c|c|}
\hline \multirow{3}{*}{ Valence group } & \multirow{3}{*}{$\begin{array}{c}\text { Serial } \\
\text { num- } \\
\text { ber }\end{array}$} & \multirow{2}{*}{\multicolumn{2}{|c|}{ Element }} & \multicolumn{4}{|c|}{ A tomic refraction factors $\left(m r^{\prime}\right)$} \\
\hline & & & & \multirow{2}{*}{$\begin{array}{l}\text { From mis- } \\
\text { cellaneous } \\
\text { compounds }\end{array}$} & \multirow{2}{*}{$\begin{array}{c}\text { From } \\
\text { "oxide } \\
\text { com- } \\
\text { pounds" } \\
\text { (table 2, } \\
\text { col. 6) } \\
0=2.50\end{array}$} & \multirow{2}{*}{$\begin{array}{l}\text { Weighted } \\
\text { average } \\
\text { from all } \\
\text { compounds }\end{array}$} & \multirow{2}{*}{$\begin{array}{c}\text { From } \\
\text { glasses } \\
\text { (table 2, } \\
\text { col. 4) } \\
\mathrm{O}=2.50\end{array}$} \\
\hline & & $A$ & $B$ & & & & \\
\hline 1 & 2 & \multicolumn{2}{|c|}{3} & 4 & 5 & 6 & 7 \\
\hline \multirow[b]{3}{*}{ Rare earths.. } & $\left\{\begin{array}{r}4 \\
4 \\
4 \\
4 \\
10\end{array}\right.$ & & $\begin{array}{l}\mathrm{Fe}^{2+} \\
\mathrm{Fe}^{3+} \\
\mathrm{Co}^{3+} \\
\mathrm{Ni} \\
\mathrm{Os}\end{array}$ & 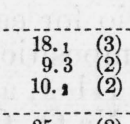 & $\begin{array}{r}11.7 \\
17.8 \\
8.8 \\
8.9 \\
22\end{array}$ & $\begin{array}{cl}11.7 & (21) \\
17.2 & (17) \\
9.2 & (10) \\
9.2 & (11) \\
22 & (1) \\
25 & (2)\end{array}$ & \begin{tabular}{l}
11.1 \\
17.4 \\
\hdashline
\end{tabular} \\
\hline & 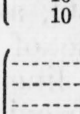 & & $\begin{array}{l}\mathrm{Pt} \\
\mathrm{Pr} \\
\mathrm{Nd} \\
\mathrm{Sm}\end{array}$ & $\begin{array}{ll}25 & (2) \\
20 & (1) \\
20 & (1) \\
19 & (1)\end{array}$ & $\begin{array}{l}20 \\
20 \\
19\end{array}$ & $\begin{array}{ll}25 & (2) \\
& \\
20 & (2) \\
20 & (2) \\
19 & (2)\end{array}$ & $\begin{array}{l}19.9 \\
19.8 \\
19.0\end{array}$ \\
\hline & & & $\begin{array}{l}\mathrm{Eu} \\
\text { Gd } \\
\text { Dy }\end{array}$ & $\begin{array}{l}21 \\
19 \\
18\end{array}$ & - & $\begin{array}{l}(1) \\
(1) \\
(1)\end{array}$ & \\
\hline & $(\ldots . .$. & & $\mathrm{Er}$ & 23 & - & $23 \quad(1)$ & 19.7 \\
\hline
\end{tabular}

The condition that the various element factors do not change for different valencies was, of course, implicitly assumed in deriving these values. Since it has long been known that such an assumption is not valid for every type of material, a careful comparison of the observed and computed specific refractions of the individual compounds was made for the purpose of revealing any systematic deviations which might reasonably be ascribed to valency. Some tendency toward systematic deviation between observed and computed specific refractions was found for compounds containing long-series elements ( $A$-subgroups) of the periodic system, but the results of the search were not on the whole conclusive, considering the probable accuracy of the observations. On the other hand, a rather close agreement was found between the atomic refraction factors, $m r^{\prime}$, as evaluated for eq 3 and those calculated directly from the oxide factors previously determined (either glassy or crystalline), by applying, in every case, the value 2.5 for the atomic refraction of oxygen. For this comparison see table 5. It should be stated, however, that of the many compounds involved in the determination of the atomic refraction factors, less than 10 percent contained elements of the $A$-subgroups (long-series elements), so that the computations are heavily weighted in favor of the $B$-subgroups (short-series elements). Therefore, granting that the factors might vary with the different valencies, the data available are too few for demonstrating such a difference by the present method.

\section{WAVELENGTH OF LIGHT}

All specific-refraction values considered up to this point have been based on the refractive index for sodium light only, but the methods of analysis used may be extended to include data involving other 
wavelengths. The most complete data available on a glass-forming material for correlating specific refraction with wavelength, $\lambda$, are those on the refractive index of vitreous silica for various wavelengths from 0.1855 to 0.7948 micron [18]. A plot of $R$ against the square of the wave number, $1 / \lambda^{2}$, (a modified application of the Cauchy dispersion formula) gives, within very narrow limits of error (expressible as \pm 0.0001 in refractive index), a straight line from about 0.3000 to 0.7000 micron for each of the seven type ratios. For many of the soda-lime-silica and soda-potash-silica glasses made at this Bureau, the refractive indices have been measured (but not yet published) for the four wavelengths $0.4358,0.5461,0.5893$, and 0.6708 micron. The Gladstone-Dale ratio for each of these wavelengths was accordingly correlated with composition, following the same system of computation used in section III-1, and the four factors, $r$ 's, thus obtained for each of the oxides, $\mathrm{Na}_{2} \mathrm{O}, \mathrm{CaO}$, and $\mathrm{K}_{2} \mathrm{O}$, as constituents, were plotted as functions of $1 / \lambda^{2}$. As in the case of the $R$ for vitreous silica, these factors were found also to be linear functions of $1 / \lambda^{2}$ within the limits of the data, that is, for each oxide, $r=\alpha+\beta\left(1 / \lambda^{2}\right), \lambda$ being expressed in microns. Table 6 gives the values thus obtained for the constants ( $\alpha$ 's and $\beta$ 's) for all four oxides in the expression

$$
R=\left(\alpha_{A}+\beta_{A} \cdot 1 / \lambda^{2}\right) p_{A}+\left(\alpha_{B}+\beta_{B} \cdot 1 / \lambda^{2}\right) p_{B}+\ldots
$$

For the same reason stated in section III-1, no attempt was made to obtain similar values of $a$ and $\beta$ for the other type ratios.

TABLE 6.-Values of constants for eq 4

\begin{tabular}{|c|c|c|c|c|}
\hline Constants & $\mathrm{SiO}_{2}$ & $\mathrm{Na}_{2} \mathrm{O}$ & $\mathrm{K}_{2} \mathrm{O}$ & $\mathrm{CaO}$ \\
\cline { 2 - 4 } & $\begin{array}{r}0.20355 \\
.001595\end{array}$ & $\begin{array}{r}0.18610 \\
.00262\end{array}$ & $\begin{array}{r}0.19540 \\
.00222\end{array}$ & $\begin{array}{r}0.21715 \\
.00257\end{array}$ \\
\hline
\end{tabular}

\section{RELATION OF THE GLADSTONE-DALE RATIO TO THE PERIODIC ARRANGEMENT OF THE ELEMENTS}

Larsen and Berman [2], in their work on the specific refractions of the oxides in minerals, stated that there was a tendency for the specific-refraction values in each group to decrease as the molecular weight increases, but that there are many exceptions. It is found that the oxide factors obtained for glasses behave in a similar manner; the exceptions referred to, however, are merely apparent, and may be removed if the data are plotted as in figure 2. In this figure each of the oxide factors $r$, obtained from the glass data (or from crystalline materials where the former were not available) is plotted, for the different valence groups, against the "serial number" of the basic element of the oxide. The respective plots show that there is a definite downward trend of the points as the serial number increases, with the qualification, however, that the points of each group first divide themselves into two subgroups which correspond to the long-series, $A$, and short-series, $B$, classification of the elements. 
Following this classification, the element factors, $m r^{\prime}$, as given in table 5, were then plotted as shown in figure 3, making separate graphs for the $A$ and $B$ elements. It appears from the graph that in general, the $B$-elements fall into a consistent periodic pattern ${ }^{4}$ : the

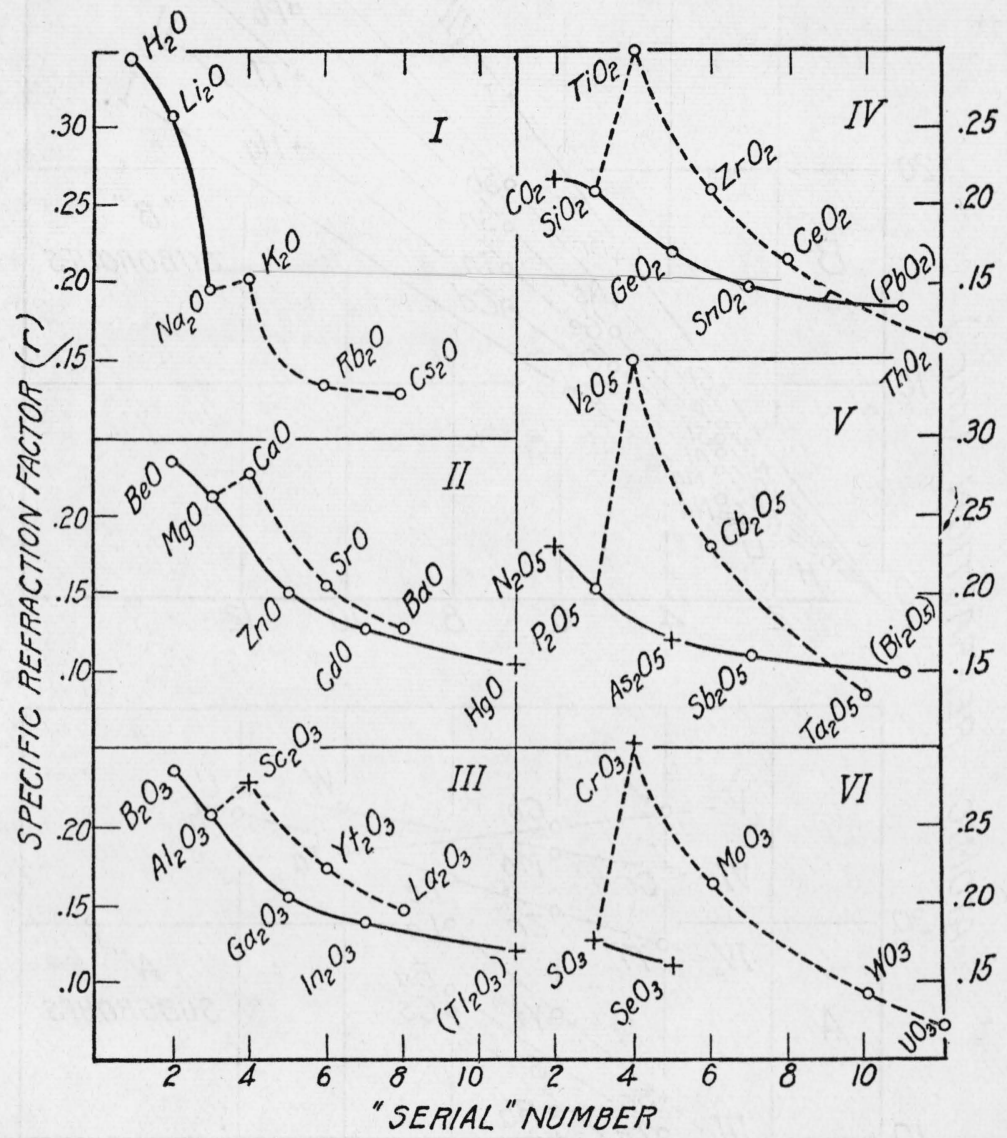

FIGURE 2.-Relation, by valence groups, between Gladstone-Dale specific refraction factors for the oxides and the periodic arrangement of the elements.

Factors from glasses are indicated by $\bigcirc$; and those from other materials by + .

points for each valence group fall on approximately a straight line passing through the origin, the slopes of the different lines increasing proportionately with the group number.

Specifically,

$$
m r^{\prime}=0.280 S(G+5),
$$

in which $S$ and $G$ are, respectively, the serial- and valence-group number of a given element.

4 The only values which do not appear to conform to this pattern are those for $\mathrm{Cu}, \mathrm{Ag}, \mathrm{S}$, and Se. These values have been omitted in the plot, but there is no readily apparent reason why they should be exceptional. 

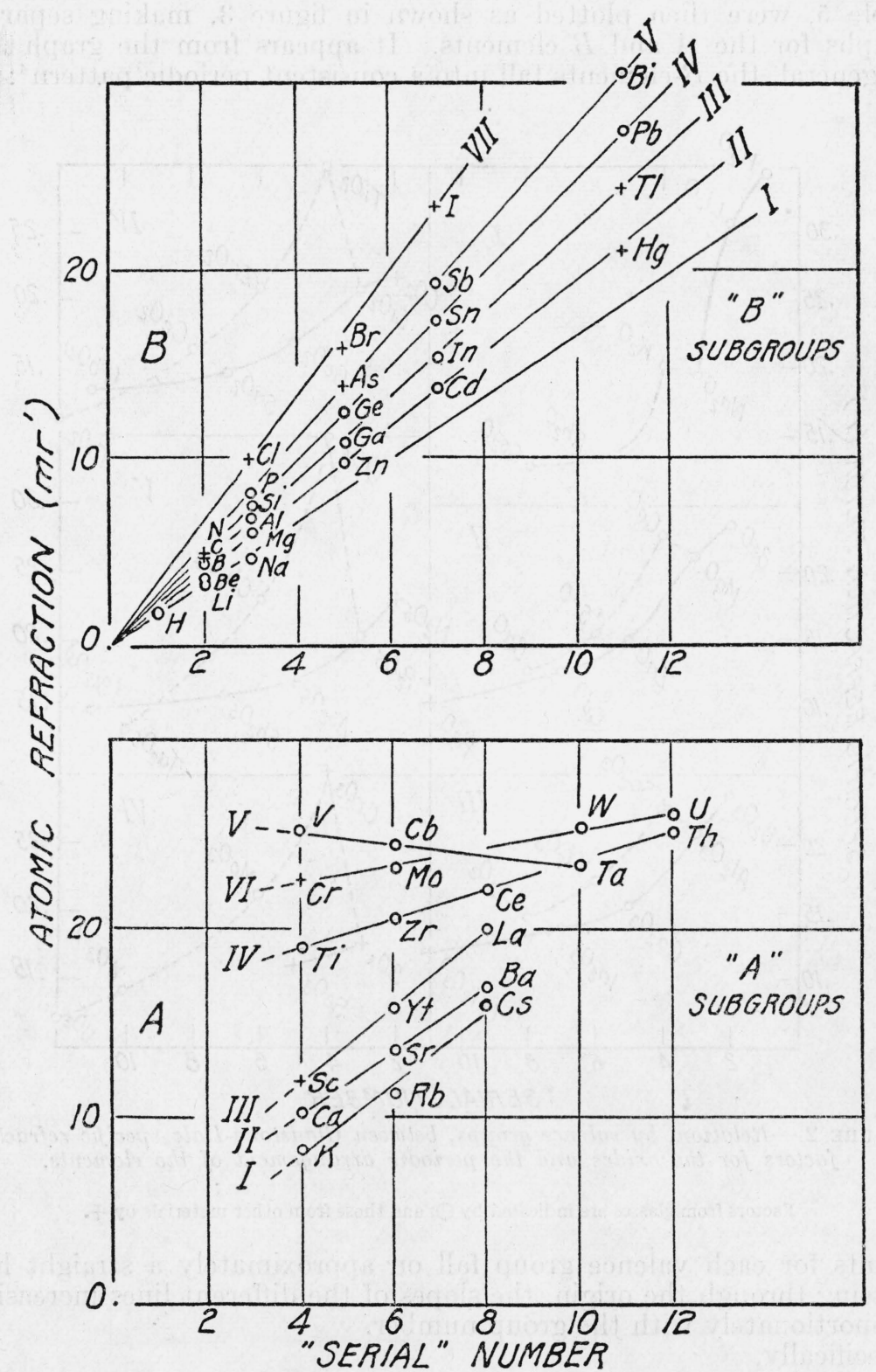

FIGURE 3.-Relation between Gladstone-Dale atomic refraction factors $\left(m r^{\prime}\right)$ of various elements and the positions of the elements in the periodic system.

Valence groups are indicated by roman numerals. Factors from glasses are indicated by $\bigcirc$, and those from other materials by + . 
The elements of the $A$-subgroups, on the other hand, do not give a plot similar to that for the $B$-subgroups. Neither an orderly relation between the different lines, nor the significance of the differing intercepts is easily discernible. The plotted values for these elements are shown in figure 3 , graph $A$. For the rare earth elements, the value for La only is plotted, as the values for all the rare earth elements are essentially the same.

The atomic refraction factors, plotted in figure 3, were originally evaluated on the assumption that they did not vary for different combinations of the elements. Since, however, such an assumption may not be justified, it was decided to study the oxide factors themselves. So the latter factors, $r$, as given in table 2 , were first reduced to "unit oxygen" by multiplying each $r$-value by the quantity $M / n_{0}$ in which $M$ and $n_{0}$ are, respectively, the corresponding molecular weight and number of oxygen atoms for the oxide. Then for each oxide the value $\mathrm{Mr} / n_{0}$ (which may be called "equivalent refraction") was plotted against the serial number of the basic element of the oxide, with the results shown in figure 4. For the $B$-elements, a configuration somewhat similar to that found for the $m r^{\prime}$-values (fig. 3) results, except that the various straight lines for the different subgroups, instead of passing through the origin, have a common intercept at 2.5 . That is,

$$
M r / n_{0}=2.5+0.560 S(1+5 / G) .
$$

Whether by coincidence or not, the intercept is numerically equal to the atomic refraction factor, $m r^{\prime}$, found previously for oxygen. At any rate, assuming the value 2.5 for oxygen, the values of $M r / n_{0}$ for $\mathrm{Tl}_{2} \mathrm{O}_{3}, \mathrm{PbO}_{2}$, and $\mathrm{Bi}_{2} \mathrm{O}_{5}$ were then calculated from the oxide factors previously found (table 2) for $\mathrm{Tl}_{2} \mathrm{O}$ (from crystals), and $\mathrm{PbO}$ and $\mathrm{Bi}_{2} \mathrm{O}_{3}$ (from glass). The values thus calculated, when plotted in figure 4, graph $B$ (points enclosed in parentheses), are found to fit $n$ their expected places, and thus the inference concerning the value for oxygen seems justified.

From a similar plot for the $A$-elements (fig. 4 , graph $A$ ) it is found that, although the points for each subgroup lie on a straight line, the intercept is different for each subgroup, the values ranging from about 3 for subgroup $I A$ to 13 for $V A$. It might be inferred, therefore, that the atomic refraction factor for oxygen would be different for each of the subgroups of $A$-elements, and that for any subgroup the numerical value of the factor would equal, at least approximately, that of the corresponding intercept, as given by figure 4, graph $A$. Some confirmation of such an inference regarding the value, or values, thus assignable to oxygen is afforded by an independent calculation of the atomic refraction factor for oxygen from the oxide factors for different states of oxidation of a particular element. For example, from the oxide factors (from crystals) for $\mathrm{CrO}_{3}$ and $\mathrm{Cr}_{2} \mathrm{O}_{3}$ (table 2), an oxygen factor of 8.7 is obtained. ${ }^{5}$ From figure 4 , graph $A$, the corresponding value of the intercept for subgroup VIA (Cr, Mo, W, and U) is found to be about 9.0. On the other hand, a similar calculation from the oxide factors (from crystals) of $\mathrm{As}_{2} \mathrm{O}_{3}$ and $\mathrm{As}_{2} \mathrm{O}_{5}$ gives a value of 2.2 for

\footnotetext{
5 That is, and

$2\left(m r^{\prime}\right)_{\mathrm{Cr}}+3\left(m r^{\prime}\right)_{\mathrm{O}}=(M r)_{\mathrm{Cr}_{3} \mathrm{O}_{3}}=152 \times 0.233$

From which $\left(m r^{\prime}\right)_{0}=8.7$.

$\left(m r^{\prime}\right)_{\mathrm{Cr}}+3\left(m r^{\prime}\right)_{\mathrm{Q}}=(M r)_{\mathrm{Cr}_{\mathrm{z}}}=100 \times 0.307$
} 

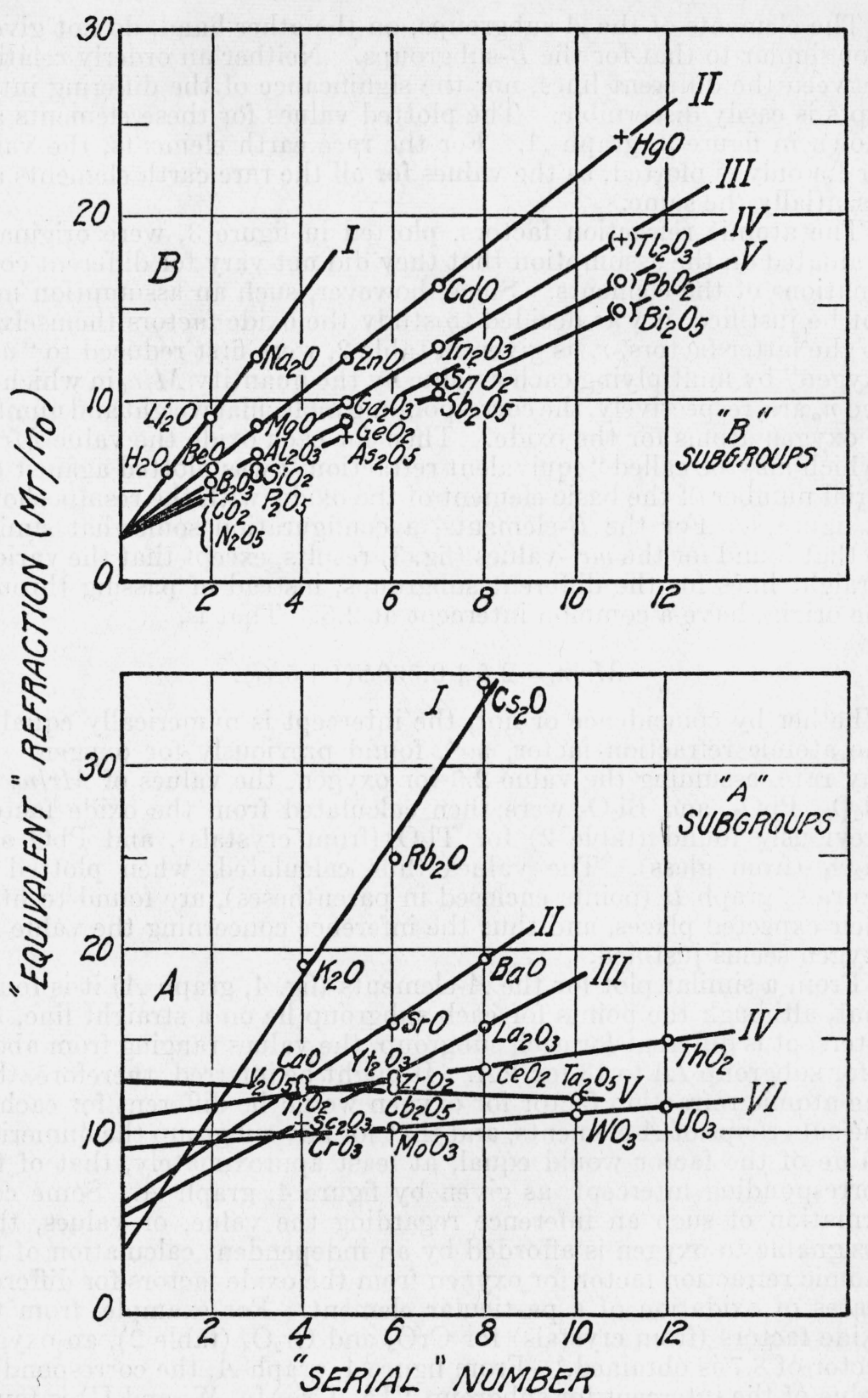

FIGURE 4.-Relation between Gladstone-Dale "equivalent refraction" factors $\left(\mathrm{Mr} / \mathrm{n}_{0}\right)$ of various oxides and the positions of the base elements in the periodic system.

Valence groups are indicated by roman numerals. Factors from glasses are indicated by $\mathrm{O}$, and those from other materials by + . 
the oxygen factor, which value corresponds to the intercept 2.5 found for all the $B$-subgroups. But an elaborate check of this nature could not be made for glass, since there are as yet no appropriate data on glasses containing the several elements in their various states of oxidation.

Considering the two methods of analysis of the data, as shown by figures 3 and 4 , the latter method seems definitely the better since the apparent anomalies involving the values for the $A$-elements may be attributed to a varying oxygen factor. In this connection, it should be noted that Gladstone and Dale themselves believed that the specific refraction factors of the elements were not constant under all circumstances, but that the factors were "modified by the manner of combination" of the elements. In principle, the second method here presented supports this belief, and, at least for the elements as occurring in glass, would furthermore identify oxygen as having the only variable factor, and then only when in combination with an $A$-element.

\section{RELATION OF DISPERSION TO SPECIFIC REFRACTION AND TO COMPOSITION}

The most important properties of an optical glass are its refractive indices for various wavelengths of light; so important, in fact, that a particular glass is, for most practical purposes, "defined" when its refractive index for the $D$-line $\left(n_{D}\right)$ and $\nu$-value $\left(\nu \equiv\left(n_{D}-1\right) /\left(n_{F}-n_{C}\right)\right)$ are specified. The latter quantity is sometimes called optical constringence, or dispersive index. But neither the refractive index nor $\nu$-value has been found to be a linear or, apparently, even a simple function of composition for glasses in general. ${ }^{6}$ It, is, therefore, not surprising that accurate quantitative information concerning a relationship between either refractive index or $\nu$-value and composition is confined to experimental glasses of comparatively simple composition. From a knowledge of specific refraction relationships, however, a method for calculating the $\nu$-value of a glass from its composition may be developed, which appears to hold within practical limits of accuracy for glasses of a wide variety of compositions.

Since, as has been shown above, $(n-1) / D$ is a linear function of composition for various wavelengths of light, the quantity $\left(n_{F}-n_{C}\right) / D$, which may be called "specific dispersion," should also vary linearly with composition; that is

$$
Q=1 / 100\left(q_{A} p_{A}+q_{B} p_{B}+\ldots\right)
$$

where $Q$ is the specific dispersion of a glass, and the $q$ 's are numerical constants representing the specific dispersion factors for the constituent oxides $A, B$, etc. If, then, eq 7 can be established experimentally and the factors ( $q$ 's) evaluated for a large number of oxides,

6 For calculating $\nu$-values of optical glasses from the compositions, Knapp [39] presents an "equation" wherein each constituent oxide is represented by eight constants.

269047-41-11 
it is comparatively simple to calculate the $\nu$-value for a glass containing any combination of such oxides from the relationship,

$$
\nu \equiv \frac{n_{D}-1}{n_{F}-n_{C}}=\frac{R}{Q},
$$

in which $R$ is the specific refraction (Gladstone-Dale) of the glass for sodium light. For an oxide, $x$, of course, $\nu_{x}$ is equal simply to $r_{x} / q_{x}$, but for a glass

$$
\nu_{\text {Glass }}=\frac{r_{A} p_{A}+r_{B} p_{B}+\ldots}{q_{A} p_{A}+q_{B} p_{B}+\ldots}
$$

in which the numerator and denominator (which are taken from eq 2 and 7 , respectively) must be calculated separately, from the values of the respective $r$ 's and $q$ 's.

Fortunately, a large body of data exists for testing the validity of eq 7 for glasses containing the four oxides, $\mathrm{SiO}_{2}, \mathrm{Na}_{2} \mathrm{O}, \mathrm{CaO}$, and $\mathrm{K}_{2} \mathrm{O}$. Morey and Merwin have reported the refractive indices for the $D$ line, the densities, and the partial dispersions $\left(n_{F}-n_{C}\right)$ for their soda-limesilica glasses [3], as well as for a series of potash-lime-silica glasses [35, p. 397]. The respective specific dispersion factors for the four oxides were accordingly evaluated statistically from these data with the results shown in table 7 . These factors yielded very much the same individual deviations between observed and calculated partial dispersions (the latter obtained by multiplying the computed specific dispersions by the observed densities) as the departures obtained by Morey and Merwin from the isodispersion lines which they presented graphically.

TABLE 7.-Specific dispersion factors, $q \equiv\left(n_{f}-n_{c}\right) / D$, for four oxides, calculated

\begin{tabular}{|c|c|c|c|c|}
\hline Source of data & $\mathrm{SiO}_{2}$ & $\mathrm{Na}_{2} \mathrm{O}$ & $\mathrm{K}_{2} \mathrm{O}$ & $\mathrm{CaO}$ \\
\hline $\begin{array}{l}\text { Morey and Merwin }[3,35] \\
\text { National Bureau of Standards }{ }^{1}\end{array}$ & $\begin{array}{r}q \times 10^{4} \\
30.7 \\
30.5\end{array}$ & $\begin{array}{r}q \times 10^{4} \\
49.5 \\
50.0\end{array}$ & $\begin{array}{r}q \times 10^{4} \\
42.0 \\
42.5\end{array}$ & $\begin{array}{r}q \times 10 \\
49.4 \\
49.1\end{array}$ \\
\hline
\end{tabular}
as constituents of glasses

1 These values derived from eq 4 ; see text, section $\mathrm{V}$.

The refractive indices for our own glasses were not measured for the particular spectral lines $F$ and $C$, but since $1 / \lambda_{F}^{2}-1 / \lambda_{C}^{2}=1.91$, the specific dispersion factors which would correspond to those from Morey and Merwin's data are easily obtained for our glasses from the relation $q=1.91 \beta$, the four $\beta$ 's having the values given in table 6 . The latter conversion depends, of course, on eq 4 . The factors thus obtained, together with those obtained from the data of Morey and Merwin, are given in table 7 , and it is evident that the agreement between the two sets of factors is very good.

Equation 7 was then extended to include data on glasses of a wide variety of compositions. Table 8 gives the specific dispersion factors, $q$, evaluated statistically from available data, as well as the dispersive indices calculated from the relation $\nu_{x}=r_{x} / q_{x}$, for all of the oxides commonly used in making optical glass, and for several other oxides not so used at present. 
TABLE 8.- "Specific aispersion" factors $(q)$ and $\nu$-values $(=r / q)$ of some oxides as constituents of glasses

\begin{tabular}{|c|c|c|c|c|c|c|}
\hline Oxide & $\begin{array}{l}r \text { (from } \\
\text { table 2) }\end{array}$ & $q \times 10^{4}$ & $\stackrel{\nu}{\nu}=r / q)$ & $\begin{array}{l}\text { Number } \\
\text { of glasses } \\
\text { containing } \\
\text { oxide }\end{array}$ & $\begin{array}{l}\text { Maximum } \\
\text { percent a }\end{array}$ & $\begin{array}{l}\text { Source of } \\
\text { data b }\end{array}$ \\
\hline $\begin{array}{l}\mathrm{Li}_{2} \mathrm{O} \\
\mathrm{Na}_{2} \mathrm{O} \\
\mathrm{K}_{2} \mathrm{O} \\
\mathrm{Rb}_{2} \mathrm{O} \\
\mathrm{Cs}_{2} \mathrm{O} \\
\mathrm{Tl}_{2} \mathrm{O}\end{array}$ & $\begin{array}{l}0.308 \\
.1937 \\
.2019 \\
.133 \\
.124 \\
.148\end{array}$ & $\begin{array}{l}70 \\
49.5 \\
42.0 \\
26 \\
22 \\
120\end{array}$ & $\begin{array}{l}44 \\
39.2 \\
48.1 \\
51 \\
56 \\
12.3\end{array}$ & $\begin{array}{r}8 \\
138 \\
49 \\
3 \\
2 \\
4\end{array}$ & $\begin{array}{l}26 \\
45 \\
38 \\
55 \\
60 \\
55\end{array}$ & $\begin{array}{c}u \\
{[3]} \\
{[35, \text { p. } 397]} \\
u \\
u \\
{[31]}\end{array}$ \\
\hline $\begin{array}{l}\mathrm{BeO} \\
\mathrm{MgO} \\
\mathrm{CaO} \\
\mathrm{ZnO} \\
\mathrm{SrO} \\
\mathrm{BaO} \\
\mathrm{PbO}\end{array}$ & $\begin{array}{l}.236 \\
.212 \\
.2270 \\
.150 \\
.154 \\
.126 \\
.134\end{array}$ & $\begin{array}{l}30 \\
45.0 \\
49.4 \\
42.0 \\
32 \\
\text { d } 26.8 \\
66.0\end{array}$ & $\begin{array}{l}78 \\
47.1 \\
46.0 \\
35.7 \\
48 \\
47.0 \\
\text { d } 20.3\end{array}$ & $\begin{array}{r}16 \\
13 \\
148 \\
38 \\
9 \\
35 \\
70\end{array}$ & $\begin{array}{l}16 \\
40 \\
56 \\
60 \\
67 \\
48 \\
90\end{array}$ & $\begin{array}{c}{[24]} \\
{[33]} \\
{[3]} \\
{[21,34]} \\
{[32]} \\
{[34]} \\
{[34,35, \text { p. 374] }}\end{array}$ \\
\hline $\begin{array}{l}\mathrm{B}_{2} \mathrm{O}_{3} \\
\mathrm{Al}_{2} \mathrm{O}_{3} \\
\mathrm{Ga}_{2} \mathrm{O}_{3} \\
\mathrm{Yt}_{2} \mathrm{O}_{3} \\
\mathrm{In}_{2} \mathrm{O}_{3} \\
\mathrm{La}_{2} \mathrm{O}_{3} \\
\mathrm{As}_{2} \mathrm{O}_{3} \\
\mathrm{Sb}_{2} \mathrm{O}_{3} \\
\mathrm{Bi}_{2} \mathrm{O}_{3}\end{array}$ & $\begin{array}{l}.236 \\
.2070 \\
.153 \\
.172 \\
.138 \\
.146 \\
.179 \\
.160 \\
.147\end{array}$ & $\begin{array}{r}\text { - } 40 \\
42 \\
39 \\
41 \\
36 \\
33 \\
37 \\
70 \\
79\end{array}$ & $\begin{array}{r}\circ 59 \\
49 \\
39 \\
42 \\
38 \\
44 \\
47 \\
23 \\
19\end{array}$ & $\begin{array}{r}40 \\
19 \\
3 \\
3 \\
3 \\
3 \\
20 \\
2 \\
5\end{array}$ & $\begin{array}{r}100 \\
52 \\
12 \\
11 \\
17 \\
20 \\
2 \\
20 \\
45\end{array}$ & $\begin{array}{c}{[34]} \\
{[34,35, \text { p. } 393]} \\
s \\
s \\
s \\
s \\
{[34]} \\
{[34]} \\
{[26]}\end{array}$ \\
\hline $\begin{array}{l}\mathrm{SiO}_{2} \\
\mathrm{TiO}_{2} \\
\mathrm{GeO}_{2} \\
\mathrm{ZrO}_{2} \\
\mathrm{SnO}_{2} \\
\mathrm{ThO}_{2}\end{array}$ & $\begin{array}{l}.2082 \\
.300 \\
.167 \\
.209 \\
.150 \\
.113\end{array}$ & $\begin{array}{c}30.5 \\
170 \\
40.1 \\
69 \\
45 \\
33\end{array}$ & $\begin{array}{l}68.2 \\
17.7 \\
41.6 \\
30.3 \\
33 \\
34\end{array}$ & $\begin{array}{l}1 \\
5 \\
1 \\
8 \\
2 \\
5\end{array}$ & $\begin{array}{r}100 \\
50 \\
100 \\
18 \\
10 \\
20\end{array}$ & $\begin{array}{c}{[18]} \\
{[35, \mathrm{p} .393]} \\
{[29]} \\
s \\
s \\
s\end{array}$ \\
\hline $\begin{array}{l}\mathrm{P}_{2} \mathrm{O}_{5} \\
\mathrm{Cb}_{2} \mathrm{O}_{5} \\
\mathrm{Ta}_{2} \mathrm{O}_{5} \\
\mathrm{WO}_{3}\end{array}$ & $\begin{array}{l}.202 \\
.230 \\
.134 \\
.142\end{array}$ & $\begin{array}{c}25.3 \\
100 \\
50 \\
58\end{array}$ & $\begin{array}{l}80 \\
23 \\
27 \\
24\end{array}$ & $\begin{array}{l}6 \\
3 \\
3 \\
4 \\
4\end{array}$ & $\begin{array}{l}71 \\
16 \\
17 \\
10\end{array}$ & $\begin{array}{c}{[34]} \\
s \\
s \\
s\end{array}$ \\
\hline
\end{tabular}

a Figures in this column indicate for each oxide the maximum percentage for which dispersion data are reported in the literature referred to; validity of the $q$-factor is not necessarily limited to this maximum.

b Figures in brackets indicate references at end of paper; $s$ indicates unpublished data on special glasses made at this Bureau (see section II); $u$ indicates other unpublished data obtained at this Bureau.

- This is the value for 100 percent only; for any percentage of $\mathrm{B}_{2} \mathrm{O}_{3}, q \times 10^{4}=0.20 \times\left(100+\% \mathrm{~B}_{2} \mathrm{O}_{3}\right)$.

$\mathrm{d}$ This value holds only through the range 0 to 60 percent of $\mathrm{PbO}$; for higher percentages, $q \times 10^{4}=0.047 \times$ $(\% \mathrm{PbO}-60)^{2}+66.0$.

The $q$-factor for each of the oxides studied, except for $\mathrm{PbO}$ and $\mathrm{B}_{2} \mathrm{O}_{3}$, appears to be constant for any concentration of the oxide. The factor for $\mathrm{PbO}$ is constant only for percentages of $\mathrm{PbO}$ up to 60 , and increases rapidly with the higher percentages. The factor for $\mathrm{B}_{2} \mathrm{O}_{3}$, on the other hand, varies proportionally with the percentage of $\mathrm{B}_{2} \mathrm{O}_{3}$ throughout the entire range 0 to 100 percent. The expressions for the $q$-factors for these two oxides are given in footnotes $d$ and $c$, respectively, of table 8 , and appear to hold accurately ${ }^{7}$ for glasses containing any amount of these oxides, as well as for pure vitreous $\mathrm{B}_{2} \mathrm{O}_{3}[35$, p. 370].

In general, the substitution of the respective $r$ - and $q$-factors in eq 8 yields $\nu$-values whose average deviation from the observed values is about 1 percent (approximately \pm 0.5 in $\nu$-value). The more accurate the observed data, the better the agreement. For instance, for 62 analyzed optical glasses of numerous types, whose

\footnotetext{
${ }^{7}$ An apparent exception is Pyrex (a heat-resisting glass of the borosilicate type), for which the computed $\nu$-value is about 4 percent higher than reported values. This discrepancy, however, may result from inadequate data rather than from any inaccuracy in the factors.
} 
$\nu$-values have been determined with care, the average difference between observed and calculated $\nu$-values is only about \pm 0.3 , which difference is comparable to the experimental error of observations made by the Pulfrich method. For glasses containing some of the more unusual oxides, however (such as $\mathrm{Cs}_{2} \mathrm{O}, \mathrm{Ga}_{2} \mathrm{O}_{3}, \mathrm{Cb}_{2} \mathrm{O}_{5}$, etc.), the precision of eq 8 appears to be much lower than that stated above, as the factors for such oxides are in most cases based on few glasses or on low concentrations of these oxides.

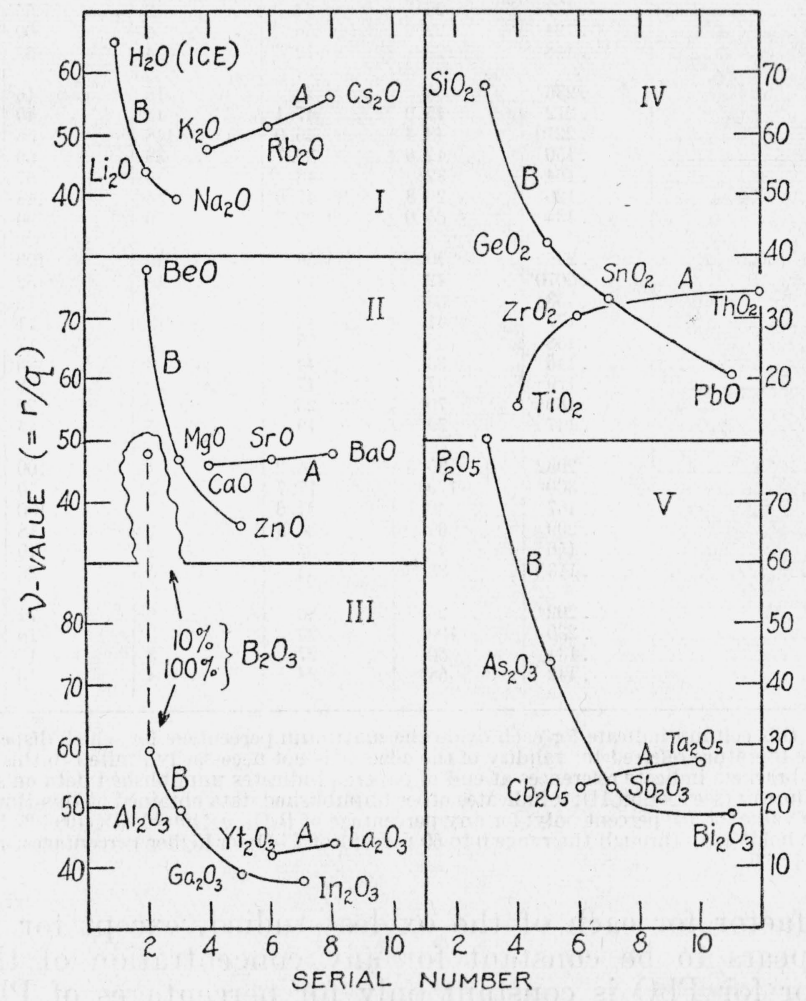

FIGURE 5.-Relation, by valence groups, between the computed $\nu$-values for the oxides in glasses and the periodic arrangement of the elements.

It is worth noting that the hypothetical $\nu$-values for $\mathrm{BeO}$ and $\mathrm{P}_{2} \mathrm{O}_{5}$, calculated from their $r$ - and $q$-factors to be 78 and 80 , respectively, are the highest of any of the oxides studied. Moreover, the similarly calculated $\nu$-value for $\mathrm{B}_{2} \mathrm{O}_{3}$ is greater than 79 for amounts of $\mathrm{B}_{2} \mathrm{O}_{3}$ up to 50 percent. The factors for these three oxides should, therefore, be most useful in designing glasses of very low dispersions.

An attempt was made to determine how the $\nu$-values for the oxides vary with the positions of the respective elements in the periodic system. The data do not appear to be extensive enough at present to justify a quantitative correlation, such as that made for the GladstoneDale specific refraction factors, but qualitatively, from an inspection of figure 5, a very striking trend may be observed: the $\nu$-values for the oxides divide themselves sharply into the $A$ - and $B$-subgroupings, corresponding to those shown above for the Gladstone-Dale factors. 
With increasing serial number the $\nu$-values in the $A$-subgroups increase, whereas those in the $B$-subgroups decrease. In general, with increasing group number the converse is true.

\section{SUMMARY}

The study of the tables and figures here presented indicates that, for glass and glass-forming materials, only the Gladstone-Dale ratio, among the seven specific refraction ratios considered, possesses to a satisfactory degree each of the following features: (1) it varies linearly with the chemical composition of the material and with the square of the wave-number of the incident light $\left(1 / \lambda^{2}\right) ;(2)$ with a few exceptions it is substantially the same for both the vitreous and crystalline states for a given composition; and (3) it is practically independent of the thermal history of the material. Each of the other type ratios failed in one or more of these particulars.

It is found that factors can be assigned to each of the various elements considered, by means of which the Gladstone-Dale ratio for glasses and crystals may be calculated. These factors are shown to be related to the periodic arrangement of the elements.

Appropriate numerical factors for the Gladstone-Dale ratio for sodium light, and for the ratio $\left(n_{F}-n_{C}\right) / D$ (which may be called specific dispersion) are presented for all of the oxides commonly used in making optical glass, as well as for several other oxides not so used at present. It is shown how these two ratios may be used for obtaining a rather accurate estimate of the dispersive index, or $\nu$-value, of any glass of known or proposed composition.

\section{REFERENCES}

Many of the data taken from the following publications have been reprinted in [35]. This circumstance is indicated below by the letter "M," followed by the page number.

[1] J. H. Gladstone and T. P. Dale, Proc. Roy. Soc. (London) 12, 448 (1863).

[2] E. S. Larsen and H. Berman, U. S. Geol. Survey Bul. 848 (1934).

[3] G. W. Morey and H. E. Merwin, J. Opt. Soc. Am. 22, 632 (1932) M383.

[4] P. Wulff and S. K. Majumdar, Z. physik. Chem. 31 [B], 319 (1936) M228.

[5] W. Biltz and F. Weibke, Glastech. Ber. 16, 131 (1938).

[6] J. T. Randall and N. Gee, J. Soc. Glass Tech. 15, 41 (1931).

[7] E. Kordes, Z. anorg. allgem. Chem. 241, 1 (1939).

[8] H. A. Lorentz, Wied. Ann. 9, 641 (1880).

[9] R. Lorenz, Wied. Ann. 11, 70 (1880).

[10] K. Lichtenecker, Physik. Z. 27, 115 (1926).

[11] J. F. Eykmann, Rec. Pays-Bas 14, 185 (1895); 15, 52 (1896).

[12] Sir Isaac Newton, Optics, book 2, pt. 3; (also P. S. Marquis de Laplace, Mécanique Céleste [4] 10, 237 (1805).

[13] W. Johst, Wied. Ann. 20, 47 (1883).

[14] W. F. Edwards, Am. Chem. J. 16, 625 (1894); 17, 473 (1895).

[15] J. C. Young, C. A. Faick, A. N. Finn, and F. W. Glaze, J. Research NBS 22, 453 (1939) RP1197.

[16] C. A. Fraick and A. N. Finn, BS J. Research 6, 993 (1931) RP320. Also J. Am. Ceram. Soc. 14, 518 (1931) M237.

[17] F. W. Glaze, J. C. Young, and A. N. Finn, BS J. Research 9, 799 (1932) RP507, M237.

[18] R. B. Sosman, The Properties of Silica (Reinhold Publishing Corporation, New York, N. Y., 1927) M371.

[19] A. Q. Tool and L. W. Tilton, Misc. Pub. INBS 102, 24 (1929). 
[20] C. A. Faick, J. C. Young, D. Hubbard, and A. N. Finn, J. Research NBS 14, 133 (1935) RP762, M238.

[21] S. English and W. E. S. Turner, J. Soc. Glass Tech. 7, 155 (1923), M232 and 382 .

[22] S. English, W. E. S. Turner, and F. Winks, J. Soc. Glass Tech. 12, 287 (1928), M234 and 383.

[23] A. R. Sheen and W. E. S. Turner, J. Soc. Glass Tech. 8, 187 (1924), M231 and 382 .

[24] C. F. Lai and A. Silverman, J. Am. Ceram. Soc. 13, 393 (1930), M240.

[25] C. A. Becker, Sprechsaal 67, 139 (1934), M241.

[26] E. R. Riegel and D. E. Sharp, J. Am. Ceram. Soc. 17, 88 (1934), M394.

[27] J. D'Ans and J. Löffler, Z. Anorg. allgem. Chem. 191, 1 (1930).

[28] L. M. Dennis and A. W. Laubengayer, J. Am. Chem. Soc. 4\%, 1945 (1925).

[29] L. M. Dennis and A. W. Laubengayer, J. Phys. Chem. 30, 1510 (1926), M405.

[30] C. J. Peddle, J. Soc. Glass Tech. 5, 72 (1921), M379.

[31] F. A. Bannister, Mineral. Mag. 21, 152 (1929).

[32] P. Eskola, Am. J. Sci. 4, 331 (1922), M375.

[33] E. S. Larsen, Am. J. Sci. 28, 263 (1909), M392.

[34] Ordnance Dept. Doc. 2037, Superintendent of Documents, Washington, D. C. (1921).

[35] G. W. Morey, The Properties of Glass (Reinhold Publishing Corporation, New York, N. Y., 1938).

[36] International Critical Tables.

[37] H. S. Washington, U. S. Geol. Survey, Professional Papers 99 (1917).

[38] W. O. George, J. Geol. 32, 353 (1924).

[39] O. Knapp, Sprechsaal 63, 61 (1930).

[40] C. G. Peters, BS Sci. Pap. 20, 635 (1926) S521.

Washington, September 11, 1940. 